\title{
Hydrological and water quality modeling in the Ontario River basins: comparison of model results
}

\author{
R. P. Rudra, B. Gharabaghi, S. Gebremeskel, S. Das \& H. Bai \\ School of Engineering, University of Guelph, Canada
}

\begin{abstract}
The applicability and validity of hydrological and water quality models has to be critically evaluated before they can be used in a basin different from where they were originally developed. Variations in physiographic characteristics and climate regime will affect the choice of a suitable hydrological model as models vary in the assumption and simplification of the natural process. These entail evaluation and if necessary modification of the original model assumptions, processes descriptions and structure to suit the river basin in consideration. The objective of this study is to investigate the applicability of widely used hydrological and water quality models under the Ontario condition in Canada. In this study the ANNualized AGricultural Non-Point Source (AnnAGNPS) and the Areal Non-Point Source Watershed Environmental Response Simulation (ANSWERS-2000) are considered. First, the uncalibrated models were applied to the Canagagigue Creek, a tributary of the Grand River basin in Ontario, Canada for a period of 1998-1999 on a daily basis. Based on parameter sensitivity analysis, the models were calibrated. Finally, the performance of the models were assessed and evaluated for their ability to simulate streamflows and sediment yield.
\end{abstract}

Keywords: water quality, hydrological modeling, Canagagigue creek, Grand River basin.

\section{Introduction}

There is mounting evidence to suggest the water quality in Grand River basin is under increasing threat. The main causes of this degradation in water quality are pollution derived from point and non-point sources. There have been some 
advances made to abate the amount of pollution coming from point sources (PS) by applying improved industrial and municipal wastewater treatment. On the other hand, the success achieved in controlling and reducing pollution form nonpoint sources (NPS) have not been as encouraging. In addition, compared to industrial pollution, agriculture is the main cause of pollution in the Grand River basin.

Understanding the causes and effects of NPS pollution has attracted much attention in recent years. Governmental agencies, academic institutions, and consulting firms are interested in methods for mapping areas contributing NPS pollution. These methods mainly involve computer-based hydrological and management models for automated, reliable, and repeatable analyses. More recently, some of these models have been linked with geographic information systems (GIS) for ease of data management or for the apportionment of complex processing tasks involving computation of spatially and temporally variable factors. Available NPS models can be used to estimate runoff, soil erosion, sediment, pesticides and nutrients transported in runoff at various sizes of spatial scale.

However, one of the problems in applying these models directly to the problem at hand is the issue of model transposability. This includes: a) the applicability of models from the basin where they are developed and tested to other basins and b) the sensitivity of models to up- and/or downscaling. One of the problems is most of the models have been developed by researchers to address specific resource scenario, while they are made available to others for more general applications (Parsons et al., [5]). Therefore, applicability and validity of hydrological and water quality models from a basin where they are originally developed and tested to a different basin has to be critically evaluated. The objective of this work is to evaluate the AnnAGNPS and ANSWERS-2000 water quality models in the Ontario river basin condition. Both models were applied to the Canagagigue Creek upstream of Floradale in the Grand River basin of Ontario to simulate runoff and sediment yield.

\section{Methodology}

\subsection{Description of the study area}

The Grand River basin covers almost $7000 \mathrm{~km}^{2}$ in area and the Grand River is one of the largest rivers in Southern Ontario, which drains to Lake Erie. The Canagagigue Creek (Fig. 1) is located between $43^{\circ} 36^{\prime} \mathrm{N}-43^{\circ} 42^{\prime} \mathrm{N}$ latitude and $80^{\circ} 33^{\prime} \mathrm{W}$ and $80^{\circ} 38^{\prime} \mathrm{W}$ longitude covering an area of $150 \mathrm{~km}^{2}$. About $80 \%$ of the study area is under agricultural activities and $10 \%$ is woodlot (Carey et al. [1]). The area upstream of the Floradale Dam with a total contributing area of about $53 \mathrm{~km}^{2}$ is selected for comparison of the two model performances. This selection was primarily based on the availability of observed flow and sediment data. These data were used for calibration and validation of the model. The topography of the study area is flat to gently undulating. A major portion of the watershed has 200 to $600 \mathrm{~mm}$ of loam or silt loam of the Huron and Harriston series overlying a loam till (Presant and Wicklund, [6], and Hoffman et al., [4]). 
Loam is the predominant soil type in the central portion of the catchment. Figure 2 shows the landuse map of the area. Agricultural practices include mixed farming with predominantly dairy farming and cropping of silage corn, small grains, some other row crops and hay. Some limited area is used to cultivate cash crops as most crops are grown for livestock feed (So and Singer, [8]). The average annual precipitation ranges from $750-1000 \mathrm{~mm}$, of which $100-200 \mathrm{~mm}$ falls as snow. The annual evaporation is about $65 \%$ of the annual precipitation. Major part of the evaporation occurs during summer season.

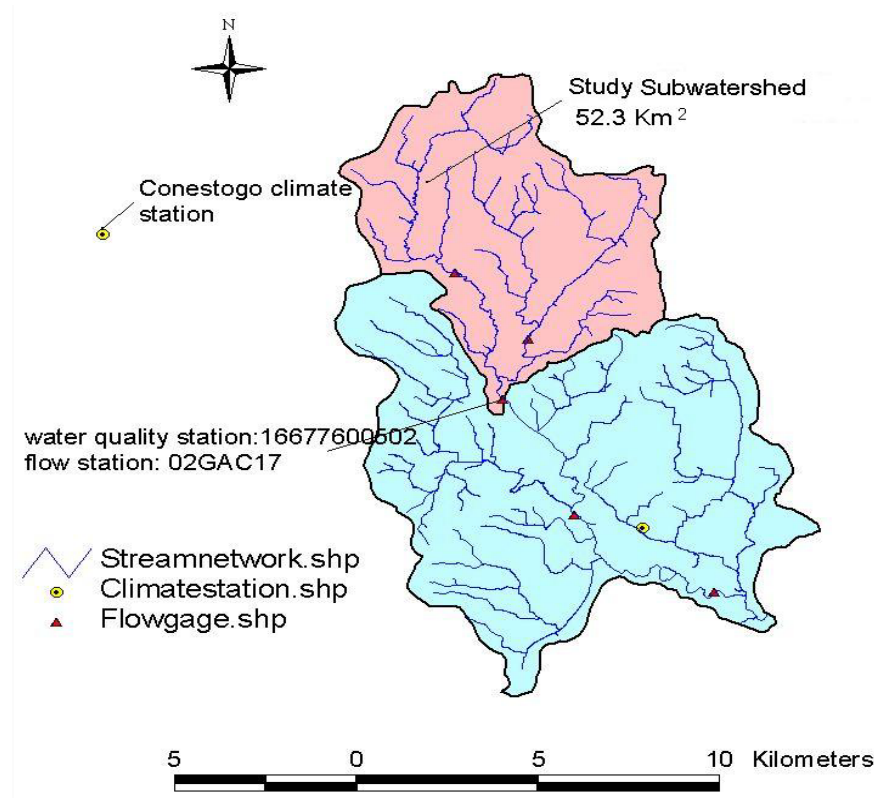

Figure 1: The location of the sub watershed inside Canagagigue watershed.

\subsection{Description of the models}

In this work two hydrological models are considered for the study area by using the same topography, landuse, soil and meteorological inputs. The topography of the study area is derived from 10-m resolution Digital Elevation Model (DEM) obtained from the Grand River Conservation Authority (GRCA). The soil GIS layer is obtained from the Ontario Ministry of Agriculture and Food (OMAF) soils database. This database includes a series of county-wise geo-spatial soil surveys data. Since both the AnnAGNPS and ANSWERS models are developed and tested in the United States, the necessary re-classification to Ontario condition was carried out. Similar to the soil data, landuse map layer was also obtained from OMAF database. Nine landuse activities on the study area were defined and are shown in Figure 2. Built-up area was considered as impervious area. Mixed system and corn system were the predominant land use during the 
study periods which occupied $38.3 \%$ and $27.9 \%$ of the entire area, respectively. Woodlot was the third dominant landuse in the watershed which covered an area $10.9 \%$.

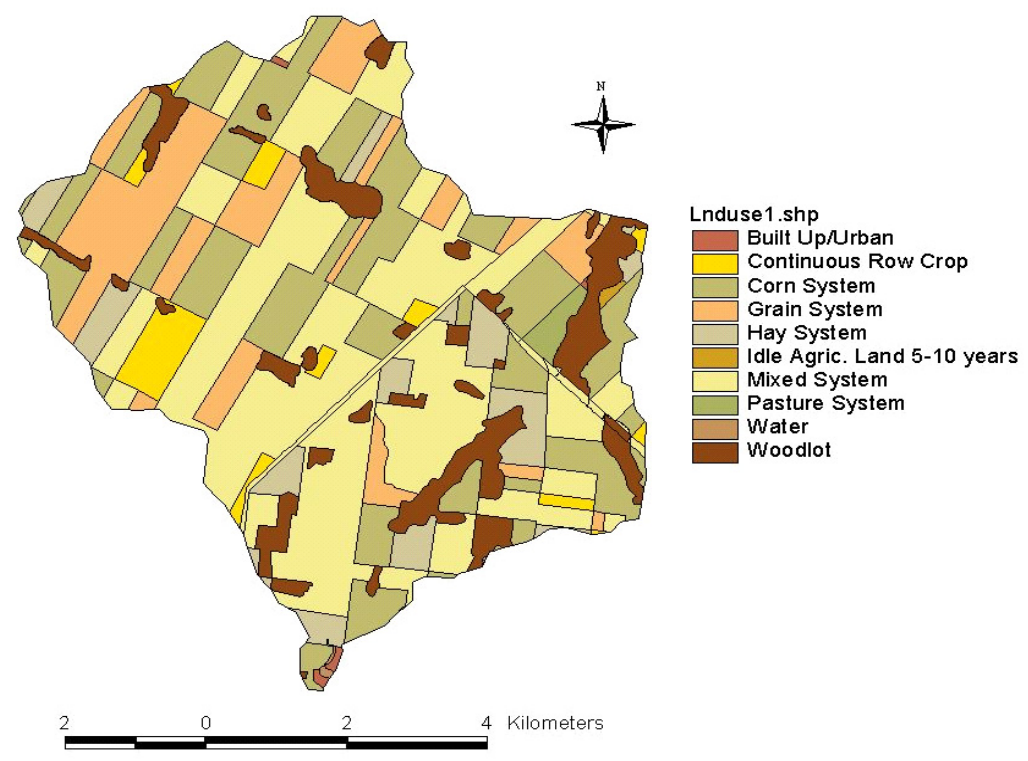

Figure 2: $\quad$ Landuse map of the Canagagigue watershed upstream of Floradale.

AnnAGNPS model is a continuous simulation, daily time step, watershed scale, pollutant loading model (Cronshey and Theurer, [2]). The hydrology part of the model is based on a water balance approach. Generated runoff is routed through the in-cell watershed flow-system on a continuous basis, allowing moisture stored in the soil to be carried over from one day to the next. Soil moisture conditions are then used to calculate the SCS curve number (CN), which forms the basis of the surface and subsurface runoff quantities for that day. The subsurface flow in AnnAGNPS considers either tile drainage or lateral subsurface flow and only occurs with the presence of an impervious layer within the soil profile. AnnAGNPS utilizes the Revised Universal Soil Loss Equation (RUSLE), for calculating the sediment delivery to a field edge when a runoff event occurs due to rainfall, irrigation, or snowmelt Renard et al. [7]. The Hydrogeomorphic Universal Soil Loss Equation (HUSLE), is used to estimate the total sediment yield leaving each field to the stream reach after deposition, Theurer and Clarke [9].

ANSWERS-2000 is a distributed parameter, physically-based, continuous simulation, field scale model. The model suitable to study long-term effectiveness of agricultural and urban best management practices (BMPs) to reduce runoff, sediment (Dillaha, et al., [3]). The model is designed for application in medium-scale heterogeneous systems where little empirical calibration information is available. The model incorporates an 
evapotranspiration and water balance modules to describe changes in soil moisture and vegetative cover between rainfall events. The Green-Ampt equation is used to compute infiltration. The model can simulate interception; surface retention/detention; infiltration; percolation; sediment detachment and transport of mixed particle size classes among others. Process-based algorithms for hydraulic movement, sediment entrainment, transport and deposition, and nutrient transport and transformation are coupled in the simulation.

\section{Results and discussion}

Both the AnnAGNPS and ANSWERS-2000 models were applied to the study area for a period of 2 years from 1998 to 1999 on a daily basis. The observed flow and sediment yield from $1 / 4 / 98$ to $31 / 10 / 98$ at the Floradale station were applied for model calibration. In addition, data from 1/4/99 to 31/10/99 observed at the same station were used for model validation. A sensitivity analysis was conducted to identify key calibrated parameters. Both models were calibrated by adjusting the sensitive parameters so that simulated values closely match observed data.

\subsection{Uncalibrated run}

Table 1 and Table 2 give the monthly output from April 1998 to October 1998 of runoff and sediment and the percentage of deviation with the observed data for AnnAGNPS and ANSWERS-2000 models respectively. (In Table 1 to Table $6 \boldsymbol{P}$ is precipitation; $\boldsymbol{Q}_{\boldsymbol{s}}$ is simulated runoff; $\boldsymbol{Q}_{\boldsymbol{o}}$ is observed runoff; $\boldsymbol{\Delta Q}$ is bias of the flow; $\boldsymbol{S}_{\boldsymbol{s}}$ is the simulated sediment; $\boldsymbol{S}_{\boldsymbol{o}}$ is observed sediment and $\boldsymbol{\Delta} \boldsymbol{S}$ is bias of the sediment.) These tables show that both models under predicted runoff. The total observed runoff for this period is $74.2 \mathrm{~mm}$ while the simulated runoff was 15.2 $\mathrm{mm}$ for AnnAGNPS and $38.7 \mathrm{~mm}$ for ANSWERS-2000 models. As far as results of sediment simulation are concerned the AnnAGNPS has over predicted the sediment yield in all months. The simulation of sediment yield by ANSWERS2000 model for the same period shows that the model has under predicted sediment in all months.

Table 1: $\quad$ Un-calibrated results of the AnnAGNPS model.

\begin{tabular}{llllllll}
\hline Mon & $\mathrm{P}(\mathrm{mm})$ & $\mathrm{Q}_{\mathrm{s}}(\mathrm{mm})$ & $\mathrm{Q}_{\mathrm{o}}(\mathrm{mm})$ & $\Delta \mathrm{Q}(\%)$ & $\mathrm{S}_{\mathrm{s}}$ (ton) & $\mathrm{S}_{\mathrm{o}}($ ton $)$ & $\Delta \mathrm{S}(\%)$ \\
\hline $4 / 98$ & 43 & 3 & 12 & -77 & 13 & 19 & -30 \\
\hline $5 / 98$ & 50 & 0 & 3 & -97 & 2 & 1 & 109 \\
\hline $6 / 98$ & 57 & 2 & 25 & -91 & 213 & 753 & -72 \\
\hline $7 / 98$ & 35 & 0 & 2 & -100 & 1 & 7 & -83 \\
\hline $8 / 98$ & 105 & 10 & 31 & -68 & 141 & 2241 & -94 \\
\hline $9 / 98$ & 34 & 0 & 0 & -100 & 1 & 0 & - \\
\hline $10 / 98$ & 33 & 0 & 0 & -38 & 3 & 1 & 500 \\
\hline sum & 356 & 15 & 74 & -80 & 374 & 3021 & -88 \\
\hline
\end{tabular}


Table 2: $\quad$ Un-calibrated result of the ANSWERS2000 model.

\begin{tabular}{lrrrrrrr}
\hline Mon & $\mathrm{P}(\mathrm{mm})$ & $\mathrm{Q}_{\mathrm{s}}(\mathrm{mm})$ & $\mathrm{Q}_{\mathrm{o}}(\mathrm{mm})$ & $\Delta \mathrm{Q}(\%)$ & $\mathrm{S}_{\mathrm{s}}$ (ton) & $\mathrm{S}_{\mathrm{o}}($ ton $)$ & $\Delta \mathrm{S}(\%)$ \\
\hline $4 / 98$ & 43 & 0 & 12 & -97 & 3 & 19 & -82 \\
\hline $5 / 98$ & 50 & 0 & 3 & -99 & 0 & 1 & -100 \\
\hline $6 / 98$ & 57 & 9 & 25 & -64 & 93 & 753 & -88 \\
\hline $7 / 98$ & 35 & 0 & 2 & -96 & 1 & 7 & -84 \\
\hline $8 / 98$ & 105 & 28 & 31 & -10 & 77 & 2241 & -97 \\
\hline $9 / 98$ & 34 & 0 & 0 & -100 & 0 & 0 & - \\
\hline $10 / 98$ & 33 & 0 & 0 & -94 & 0 & 1 & -100 \\
\hline sum & 356 & 38 & 74 & -49 & 175 & 3021 & -94 \\
\hline
\end{tabular}

\subsection{Calibrated run}

Since the performance of the erosion component was not satisfactory in the uncalibrated phase, parameter calibration was done to reduce errors in the predicted sediment. Table 3 and Table 4 show the monthly simulation results and the deviation with the observed data after calibration of runoff and sediment for AnnAGNPS and ANSWERS-2000 models respectively. The result given in Table 3 shows that by using AnnAGNPS the simulated runoff has increased and the sediment yield has been decreased by small amount. For sediment, due to the observed data in May and September, a huge deviation between the simulated and observed value still exists. Coefficient of determination $\left(\mathrm{R}^{2}\right)$ values between simulated and observed amount of runoff and sediment are 0.93 and 0.91 respectively. From the results given in Table 4, it can be said that calibration of the ANSWERS-20000 model significantly improved the accuracy of sediment yield results, with slight deterioration in the prediction of runoff amount. A statistical analysis between the predicted runoff amount and sediment yield resulted in determination coefficient of 0.76 for runoff and 0.63 for sediment yield.

Table 3: $\quad$ Calibrated run using the AnnAGNPS model.

\begin{tabular}{lrrrrrrrr}
\hline Mon & $\mathrm{P}(\mathrm{mm})$ & $\mathrm{Q}_{\mathrm{s}}(\mathrm{mm})$ & $\mathrm{Q}_{\mathrm{o}}(\mathrm{mm})$ & $\Delta \mathrm{Q}(\%)$ & $\mathrm{S}_{\mathrm{s}}$ (ton) & $\mathrm{S}_{\mathrm{o}}($ ton $)$ & $\Delta \mathrm{S}(\%)$ \\
\hline $4 / 98$ & 43 & 4 & 12 & -70 & 12 & 3 & 250 \\
\hline $5 / 98$ & 50 & 0 & 3 & -94 & 4 & 0 & - \\
\hline $6 / 98$ & 57 & 4 & 25 & -86 & 219 & 93 & 136 \\
\hline $7 / 98$ & 35 & 0 & 2 & -95 & 1 & 1 & -36 \\
\hline $8 / 98$ & 105 & 12 & 31 & -62 & 130 & 77 & 69 \\
\hline $9 / 98$ & 34 & 0 & 0 & -29 & 1 & 0 & - \\
\hline $10 / 98$ & 33 & 1 & 0 & 213 & 4 & 0 & - \\
\hline sum & 356 & 20 & 74 & -73 & 370 & 175 & 112 \\
\hline
\end{tabular}


Table 4: $\quad$ Calibrated run using the ANSWERS2000 model.

\begin{tabular}{lrrrrrrrr}
\hline Mon & $\mathrm{P}(\mathrm{mm})$ & $\mathrm{Q}_{\mathrm{s}}(\mathrm{mm})$ & $\mathrm{Q}_{\mathrm{o}}(\mathrm{mm})$ & $\Delta \mathrm{Q}(\%)$ & $\mathrm{S}_{\mathrm{s}}$ (ton) & $\mathrm{S}_{\mathrm{o}}($ ton $)$ & $\Delta \mathrm{S}(\%)$ \\
\hline $4 / 98$ & 43 & 0 & 12 & -98 & 0 & 3 & -100 \\
\hline $5 / 98$ & 50 & 0 & 3 & -99 & 0 & 0 & - \\
\hline $6 / 98$ & 57 & 8 & 25 & -67 & 79 & 93 & -15 \\
\hline $7 / 98$ & 35 & 0 & 2 & -98 & 2 & 1 & 46 \\
\hline $8 / 98$ & 105 & 25 & 31 & -21 & 243 & 77 & 215 \\
\hline $9 / 98$ & 34 & 0 & 0 & -100 & 0 & 0 & - \\
\hline $10 / 98$ & 33 & 0 & 0 & -94 & 0 & 0 & - \\
\hline sum & 356 & 34 & 74 & -55 & 324 & 175 & 85 \\
\hline
\end{tabular}

Table 5: $\quad$ AnnAGNPS model result for the validation period.

\begin{tabular}{rrrrrrrr}
\hline Mon & $\mathrm{P}(\mathrm{mm})$ & $\mathrm{Q}_{\mathrm{s}}(\mathrm{mm})$ & $\mathrm{Q}_{\mathrm{o}}(\mathrm{mm})$ & $\Delta \mathrm{Q}(\%)$ & $\mathrm{S}_{\mathrm{s}}$ (ton) & $\mathrm{S}_{\mathrm{o}}$ (ton) & $\Delta \mathrm{S}(\%)$ \\
\hline $4 / 99$ & 45 & 5 & 25 & -81 & 23 & 19 & 25 \\
\hline $5 / 99$ & 66 & 3 & 5 & -35 & 48 & 2 & 2432 \\
\hline $6 / 99$ & 108 & 16 & 22 & -26 & 132 & 67 & 98 \\
\hline $7 / 99$ & 65 & 8 & 13 & -38 & 37 & 26 & 42 \\
\hline $8 / 99$ & 56 & 2 & 1 & 122 & 20 & 0 & - \\
\hline $9 / 99$ & 70 & 4 & 4 & 4 & 64 & 9 & 604 \\
\hline $10 / 99$ & 71 & 11 & 13 & -21 & 88 & 50 & 78 \\
\hline sum & 481 & 49 & 84 & -42 & 412 & 172 & 140 \\
\hline
\end{tabular}

\subsection{Model validation}

The validation of a model is the final step to independently verify the performance of a model. Once a model is successfully validated, it can be used to select management practice, to develop remedial implementation strategies and to evaluate future water resources planning. In this work measured flow and sediment data, at the outlet of the watershed, for the year 1999 were used to validate the model. Tables 5 and Table 6 give the output of both models and the 1999 observed climate data for AnnAGNPS and ANSWERS-2000 models respectively. The simulated runoff by both models still under predicted than the observed runoff. The observed runoff is $84 \mathrm{~mm}$ where as the simulated runoff are $49 \mathrm{~mm}$ and $17 \mathrm{~mm}$ for AnnAGNPS and ANSWERS-2000 models respectively with the coefficient of determination is $\mathrm{R}^{2}=0.83$. Thus it could be concluded that the model consistently under predicted the runoff. The deviation for simulated sediment with the observed was $140 \%$ with coefficient of determination $\left(\mathrm{R}^{2}\right)$ is 0.79 that shows the AnnAGNPS model is over predicting the sediment yield in validation phase too The validation results show the 
improvement in sediment prediction by the model. The results summarized in Table 5 indicate that model still under predicted runoff with an overall percent error of about $42 \%$. The ANSWERS-2000 model still under predicts the runoff volume by $79 \%$ and the coefficient of determination of 0.82 . It also under predicts the sediment yield by $29 \%$ which is better than the calibration period and a coefficient of determination of 0.53 is obtained.

Table 6: $\quad$ ANSWERS2000 model result for the validation period.

\begin{tabular}{lrrrrrrr}
\hline Mon & $\mathrm{P}(\mathrm{mm})$ & $\mathrm{Q}_{\mathrm{s}}(\mathrm{mm})$ & $\mathrm{Q}_{\mathrm{o}}(\mathrm{mm})$ & $\Delta \mathrm{Q}(\%)$ & $\mathrm{S}_{\mathrm{s}}$ (ton) & $\mathrm{S}_{\mathrm{o}}($ ton $)$ & $\Delta \mathrm{S}(\%)$ \\
\hline $4 / 99$ & 45 & 0 & 25 & -98 & 2 & 19 & -89 \\
\hline $5 / 99$ & 66 & 1 & 5 & -71 & 9 & 2 & 347 \\
\hline $6 / 99$ & 108 & 8 & 22 & -64 & 64 & 67 & -4 \\
\hline $7 / 99$ & 65 & 5 & 13 & -64 & 37 & 26 & 43 \\
\hline $8 / 99$ & 56 & 0 & 1 & -83 & 0 & 0 & - \\
\hline $9 / 99$ & 70 & 1 & 4 & -80 & 3 & 9 & -65 \\
\hline $10 / 99$ & 71 & 2 & 13 & -87 & 7 & 50 & -86 \\
\hline sum & 481 & 17 & 84 & -79 & 121 & 172 & -29 \\
\hline
\end{tabular}

\section{Conclusion}

In this paper the application and evaluation of two widely used water quality models are presented for their ability to simulate runoff and sediment. The models were applied in the Canagagigue basin upstream of Floradale reservoir. GIS data of landuse, soil and DEM from the study area together with meteorological data were applied to both models. Before the models were applied for simulation of sediment and runoff, they were calibrated by using observed streamflow data for the year 1998 on daily basis. Then finally they were verified for the period of 1999 using daily observed data. The AnnAGNPS model under predicted the simulated runoff and over predicted the sediment yield. Runoff curve number is the most sensitive parameter in the model as it has a greater impact on runoff than other parameters and runoff controls the detachment and transportation of other components from a watershed. Calibration and validation results show that the model is capable of simulating the runoff amount and sediment yield fairly well for the cold and temperate region like Ontario. Selection of the model inputs parameter needs a careful attention specially while running for long term period, as it is sensitive to input parameters. The calibration and verification results of the ANSWERS-2000 model indicate that it can simulate runoff and sediment yield from agricultural area in Ontario conditions with reasonable accuracy during non-snow seasons. It also can identify location of potential sources of sediments in a watershed. 
However, for both models it is necessary to do a more comprehensive analysis using long term data for proper assessment of model performance.

\section{References}

[1] Carey, J.H., M.E. Fox, B.G. Brownlee, J.L. Metcalfe, P.D. Mason and W.H. Yerex. 1983. The Fate and effects of contaminants in Canagagigue Creek-1. Stream ecology and identification of major contaminants. Environment Canada. Scientific series No. 135. 37p.

[2] Cronshey, R.G. and F.G. Theurer, 1998. AnnAGNPS-Non Point Pollutant Loading Model. In Proceedings First Federal Interagency Hydrologic Modeling Conference. 19-23 April 1998, Las Vegas, NV

[3] Dillaha, T.A., C.D. Heatwole, M.R. Bennett, S. Mostaghimi, V.O. Shanholtz, and B.B. Ross. 1988. Water Quality Modeling for Nonpoint Source Pollution Control Planning: Nutrient Transport. Blacksburg, VA: prepared for the Virginia Division of Soil and Water Conservation; Virginia Polytechnic Institute and State University, Dept. of Agricultural Engineering; 117 p.; Rep. No. SW-88-02.

[4] Hoffman, D.W., Matthews, B.C. and Wicklund, R.E. 1963: Soil Survey of Wellington County, Ontario; Report No. 35 of the Ontario Soil Survey; Research Branch, Canada Department of Agriculture and The Ontario Agricultural College, 69p. Accompanied by two coloured soil maps, scale $1: 63,360$.

[5] Parsons, J. E., Sabbagh, G. J., Heatwole, C. D. and Evans, R. O., 2001. Evaluation criteria for water quality models. In: Agricultural non-point source water quality models, (Eds. Parsons, J. E., Thomas, D. L. and Huffman, R. L.): 23-27

[6] Presant, E.W and R.E. Wicklund. 1971. The Soils of Waterloo County; Report No. 44 of the Ontario Soil Survey; Research Branch, Canada Department of Agriculture, Department of Soil Science, University of Guelph, and The Ontario Department of Agricultural and Food, 104p. Accompanied by soil maps, scale 1:20,000.

[7] Renard, K.G., G.R. Foster, G.A. Weesies, D.K. McCool, and D.C. Yoder, coordinators, 1997. Predicting soil erosion by water: A guide to conservation planning with the Revised Universal Soil Loss Equation (RUSLE). USDA AgricultureHandbook No. 703.

[8] So, S.K. and S.N. Singer. 1982. Grand River basin water management study technical report series Report \#27: Rural non-point source pollution and control, prepared for the Grand River Implementation Committee. Water Resources Branch, Ontario Ministry of the Environment. 156p

[9] Theurer, F.D. and C.D.Clarke. 1991. Wash load component for sediment yield modeling. In Proceedings of the fifth federal interagency sedimentation conference, March 18-21, 1991, pg. 7-1 to 7-8. 